Check for updates

Cite this: RSC Adv., 2017, 7, 48526

Received 18th August 2017

Accepted 9th October 2017

DOI: 10.1039/c7ra09137k

rsc.li/rsc-advances

\title{
Corrosion properties of steel in 1-butyl-3- methylimidazolium hydrogen sulfate ionic liquid systems for desulfurization application $\dagger$
}

\begin{abstract}
Qian Zeng, Jinwei Zhang, Hongye Cheng, (D)* Lifang Chen and Zhiwen Qi
Ionic liquids (IL) become more promising in industrial applications, especially in desulfurization processes. It is of great importance to investigate their corrosivity to steel and the effect of steel corrosion on desulfurization performance. In this work, the corrosion behavior of two typical metals, namely mild steel and stainless steel, in 1-butyl-3-methylimidazolium hydrogen sulfate ([BMIM]HSO $\mathrm{H}_{4}$ ) IL systems for desulfurization application were investigated by weight loss and surface analyses. The model oil can inhibit the IL corrosivity, while the presence of water or $\mathrm{H}_{2} \mathrm{O}_{2}$ enhances the corrosion degree. The bonding information of $\left[\mathrm{BMIM}_{\mathrm{HSO}} \mathrm{HS}_{4}\right.$ adsorbed on a steel surface was confirmed using ATR-FTIR. It was found that the IL film is mainly adsorbed on the metal surface by the interaction of the imidazolium group of the cation and $\mathrm{HSO}_{4}{ }^{-}$of the anion with the steel surface. From the ICP-MS and Raman analyses, the primary component of corrosion products is iron sulfate (ferric sulfate for mild steel and ferrous sulfate for stainless steel). Localized corrosion (pitting and/or intergranular corrosion) appears on steel surface from SEM observation, which could be a serious safety risk to the [BMIM] $\mathrm{HSO}_{4}$-based desulfurization systems for industrial application. The corrosion has a side effect on the desulfurization performance of $[\mathrm{BMIM}] \mathrm{HSO}_{4}$.
\end{abstract}

\section{Introduction}

Ionic liquids (ILs), also known as room-temperature molten salts, have received extensive interest due to their unique properties and potential for diverse applications. Compared with traditional solvents, ILs can offer remarkable advantages in intrinsic ionic conductivity and having a wide electrochemical window, high thermal stability, non-flammability, and negligible vapor pressure. Since their physical and chemical properties can be adjusted by combination of different cations and anions, ILs are considered as a task-specific liquid and have potential in a number of fields such as separation, organic synthesis, catalysis, nanotechnology, electrochemistry, and so on. ${ }^{1-3}$

In recent years, ILs have attracted interest in extractive desulfurization (EDS) and oxidative desulfurization (ODS) processes, as more stringent environmental regulations have been implemented all over the world to restrict the sulfur content in fuels $(<10 \mathrm{ppm})^{4,5}$ EDS employs ILs as solvent to extract sulfur compounds from fuels, ${ }^{6}$ while in ODS, sulfur compounds are oxidized to their corresponding sulfoxides and

Max Planck Partner Group at the State Key Laboratory of Chemical Engineering, School of Chemical Engineering, East China University of Science and Technology, Shanghai 200237, China. E-mail: hycheng@ecust.edu.cn

$\dagger$ Electronic supplementary information (ESI) available. See DOI: 10.1039/c7ra09137k sulfones and then extracted by ILs..$^{7-9}$ Compared to EDS, ODS is more efficient since sulfoxides or sulfones are more easily extracted by ILs. Owing to the advantages of low cost, easy preparation, and high desulfurization efficiency, 1-butyl-3methylimidazolium hydrogen sulfate ([BMIM] $\left.\mathrm{HSO}_{4}\right)$ IL is screened as an ideal candidate for industrial desulfurization application and has been investigated in previous studies. ${ }^{10-12}$ $[\mathrm{BMIM}] \mathrm{HSO}_{4}$ has strong acidity due to its Brönsted acid site, which is a proton-donor and can be used as the catalyst to facilitate the oxidization of sulfur compounds in ODS. ${ }^{13} \mathrm{H}_{2} \mathrm{O}_{2}$ is the most commonly used oxidant in ODS, because of its environmental friendliness and affordable cost. ${ }^{14}$

When applying ILs in industrial processes, they are in contact with metals and alloys in pipes and units of reactor, separation and storage tank. The corrosivity of ILs to metallic material is essential, which may cause problems of leakage, abnormal plant shutdown, and environmental pollution. Therefore, industrial application of ILs requires a better understanding of their corrosivity to metals.

The corrosion characteristics and mechanism of metallic materials in ILs are quite different from those in conventional environments. ${ }^{15}$ Uerdingen et al. reported the corrosion behavior of metals in various ILs and investigated the effect of water content on corrosion. ${ }^{16}$ It proved that stainless steel exhibited the best corrosion resistance in all ILs and the presence of water can significantly enhance the corrosivity of IL media. Molchan et al. studied the corrosion behavior of mild 
steel in ILs for $\mathrm{CO}_{2}$ capture application. ${ }^{\mathbf{1 7}}$ The morphological changes were monitored by scanning electron microscopy (SEM), and the corrosion products including ferrites, sulfates, carbonates and oxides were detected by micro-Raman analysis. Diamanti et al. investigated the corrosion behavior of steel alloys in several imidazolium-based ILs. ${ }^{18}$ The effect of the cation and anion of ILs and the water content were studied. Since the corrosion phenomena vary with the type of ILs and water content in IL solutions, ${ }^{19,20}$ the investigation of corrosion characteristics in certain IL systems is strongly needed.

Up to now, there is no report of the corrosion behavior of steel in [BMIM] $\mathrm{HSO}_{4}$ IL for EDS and ODS applications. [BMIM] $\mathrm{HSO}_{4}$ has strong acidity, which may cause severe corrosion problems. However, because of the good corrosion inhibition of imidazolium group, ${ }^{21,22}$ the corrosion behavior of $[\mathrm{BMIM}] \mathrm{HSO}_{4}$ should be different from other acidic environments. Moreover, the existence of water and $\mathrm{H}_{2} \mathrm{O}_{2}$ may facilitate the corrosion of steel in [BMIM] $\mathrm{HSO}_{4} \cdot{ }^{23,24}$

In the present work, the corrosion behavior of steels including mild steel and stainless steel in $[\mathrm{BMIM}] \mathrm{HSO}_{4}$ and [BMIM] $\mathrm{HSO}_{4}$-based desulfurization systems were investigated in details. In desulfurization experiment, model oil is always used to investigate the desulfurization mechanism, ${ }^{25}$ which is prepared by dissolving a certain amount of sulfur compounds in n-heptane or n-octane. ${ }^{26-28}$ Meanwhile, water and $\mathrm{H}_{2} \mathrm{O}_{2}$ are also the common components in desulfurization systems..$^{\mathbf{9} 29} \mathrm{~A}$ certain amount of water within a range $(<10 \mathrm{wt} \%)$ has a promoted effect on desulfurization efficiency using ILs, ${ }^{30}$ while $\mathrm{H}_{2} \mathrm{O}_{2}$ is employed as oxidant in ODS. Therefore, the effect of the addition of model oil, water, and $\mathrm{H}_{2} \mathrm{O}_{2}$ in [BMIM] $\mathrm{HSO}_{4}$ on the corrosion behavior of steels were studied and a possible mechanism was proposed in this work. Finally, the side effect of corrosion on [BMIM] $\mathrm{HSO}_{4}$-based desulfurization process was investigated.

\section{Experimental}

\subsection{Materials}

Two commonly used metals, i.e. Q235 steel and 316L stainless steel (SS316L) obtained from the Biosteel Research Institute were studied. Q235 is a kind of mild steel (MS) with a ferritepearlite structure and with a chemical composition (in wt\%) of $0.18 \mathrm{C}, 0.60 \mathrm{Mn}, 0.22 \mathrm{Si}, 0.016 \mathrm{P}, 0.02 \mathrm{~S}$, and Fe balance. SS316L is a kind of austenitic stainless steel, containing (in wt\%) 0.018C, 1.11Mn, 0.026P, 0.001S, 0.53Si, 17.4Cr, 11.1Ni, 2.16Mo, and Fe balance. Each specimen with dimensions of $10 \mathrm{~mm} \times$ $10 \mathrm{~mm} \times 3 \mathrm{~mm}$ was abraded consecutively with 400, 600, 800, 1000, and 1200 grit silicon carbide abrasive paper, then washed with deionized water and degreased in acetone. The surface of each specimen is $3.2 \mathrm{~cm}^{2}$.

[BMIM] $\mathrm{HSO}_{4}$ (the chemical structure shown in Fig. 1) with purity higher than $99 \mathrm{wt} \%$ (water content $0.7 \mathrm{wt} \%$ ) was purchased from Lanzhou Institute of Chemical Physics, Chinese Academy of Sciences. Hydrogen peroxide (30 wt\%) and n-heptane (98.5 wt\%) were purchased from Aladdin Chemical Co., Ltd. Dibenzothiophene (DBT) (99 wt\%) was purchased

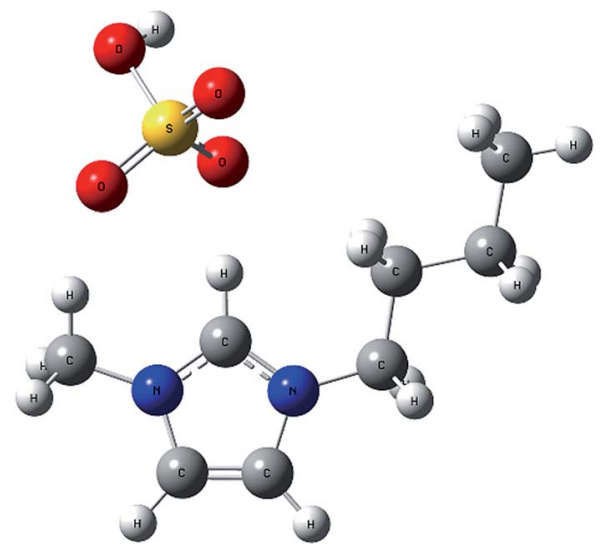

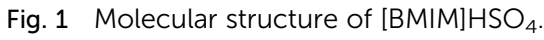

from Adamas Reagent Company Co., Ltd (Shanghai, China). The chemicals were used as received.

\subsection{Methods}

$\mathrm{n}$-Heptane is taken as model oil (MO) component with DBT as the representative sulfur compound. Model oil was prepared by adding DBT to n-heptane, with the sulfur content of $500 \mathrm{ppm}$. To study the corrosion properties of steel in pure [BMIM] $\mathrm{HSO}_{4}$ as well as in EDS and ODS processes, four IL solutions were used for immersion experiments as the following: (i) IL, (ii) IL + $\mathrm{MO}$, (iii) $\mathrm{IL}+\mathrm{MO}+\mathrm{H}_{2} \mathrm{O}$, and (iv) $\mathrm{IL}+\mathrm{MO}+\mathrm{H}_{2} \mathrm{O}_{2}$. The amount of IL for each solution was $60 \mathrm{~g}$, while the amount of $\mathrm{MO}$ in the solutions (ii), (iii), and (iv) was $300 \mathrm{~g} .6 \mathrm{~g} \mathrm{H} \mathrm{H}_{2} \mathrm{O}$ and $6 \mathrm{~g} \mathrm{H}_{2} \mathrm{O}_{2}$ were added into the solutions (iii) and (iv), respectively.

In each immersion test, three specimens were fixed on the polytetrafluoroethylene holder in a conical flask, in order to suspend and immerse them in the IL media and expose their surfaces to the media as much as possible. The area of the holder being in contact with specimen is rather small that it can be neglected for the calculation of corrosion rate. In desulfurization process, the mixture is a biphasic system, because IL is not soluble in the model oil. Therefore, in immersion tests, a shaking bed is used to adequately mix up the IL phase and oil phase, making the specimen corroded just like in the real desulfurization process. The flask was sealed and fixed in the shaking bed with a frequency of $90 \mathrm{rpm}$ and temperature of $45{ }^{\circ} \mathrm{C}$. After 14 day immersion experiment, the specimens were taken from the solution for further Fourier transform infrared spectroscopy (FTIR) and Raman analyses. Then, according to the ASTM G31 norm, ${ }^{31}$ the specimens were scrubbed with a bristle brush to remove corrosion products, rinsed in deionized water to remove the IL solution, washed with acetone to clean the model oil, dried in air, and weighed accurately for the weight loss measurement and SEM analyses. ${ }^{31-35}$

After corrosion of mild steel and stainless steel for 14 days, the types and the contents of metal ions in all the four IL systems were measured by Inductively Coupled Plasma Mass Spectrometry (PerkinElmer) and spectrophotometer (SigmaAldrich). 
The acidity of different IL systems before and after corrosion of mild steel and stainless steel for 14 days was evaluated from the determination of Hammett acidity function. The ILs from different systems and the indicator (4-nitroaniline, $\mathrm{p} K(\mathrm{I}) \mathrm{aq}=$ 0.99) were dissolved in the dimethyl sulfoxide (DMSO) at a concentration of $5 \times 10^{-5} \mathrm{~mol} \mathrm{~L}^{-1}$. The solutions were shaken vigorously and left to stand for $6 \mathrm{~h}$. Then, their spectra were recorded on a P-General UV-visible spectrophotometer.

A set of 33 day immersion tests were conducted to investigate the corrosion kinetics of stainless steel in [BMIM] $\mathrm{HSO}_{4}$ IL solutions. The specimens were periodically removed from IL solutions, cleaned according to ASTM G31 norm, and then weighed accurately. ${ }^{31}$

FTIR spectra were recorded using a Perkin Elmer Spectrum 100 spectrometer in a reflection mode with an Attenuated Total Reflectance (ATR) attachment utilizing a diamond prism. ATRFTIR spectroscopy is an acknowledged technique which has been widely used to analyze the nature of bonding for organic complexes adsorbed on the metal surface. ${ }^{36,37}$ The spectral resolution was $1 \mathrm{~cm}^{-1}$ and the wavenumber range of 650$4000 \mathrm{~cm}^{-1}$ was utilized to collect the IR spectra. The recorded spectra were compared with those of the substances selected from the Sadtler Handbook of Infrared Spectra. ${ }^{38}$ The corrosion products were detected by micro-Raman (HORIBA Jobin Yvon LabRAM HR800 system). Laser light with the wavelength of $514.5 \mathrm{~nm}$ was used. A long working distance lens with the magnification of $50 \times$ was applied to detect the scattered light and focus the laser spot on specimen surface. The surface morphology of the specimens before and after immersion tests were examined by SEM (Hitachi S3400N).

In order to have an intuitive understanding of the corrosion behavior of steel in IL solutions, the weight loss measurements for mild steel and stainless steel in four [BMIM] $\mathrm{HSO}_{4}$-based systems were adopted. A modified experimental plan was performed based on ASTM G31-72. ${ }^{31}$ To get high reliability and reproducibility, the processed specimens were immersed in IL solutions in triplicate, and the weight losses of three specimens were recorded.

The weight loss rates were calculated from the following equation:

$$
\nu=\left(W_{0}-W_{1}\right) / S t
$$

where $\nu$ represents the weight loss rate $\left(\mathrm{g} \mathrm{m}^{-2} \mathrm{~h}^{-1}\right), W_{0}$ is the weight $(\mathrm{g})$ of the steel specimens before immersion in IL solutions, and $W_{1}$ is the weight $(\mathrm{g})$ of steel specimens after immersion. $S$ is the total area in $\mathrm{m}^{2}$ of one steel specimen, and $t$ refers to the immersion time (h).

With the weight loss rate, the average corrosion rate on the basis of equivalent thickness loss can be calculated as reported in the literature: $:^{39,40}$

$$
B=8.76 \nu / \rho
$$

where $B$ represents the corrosion depth rate $\left(\mathrm{mm} \mathrm{y}^{-1}\right), \nu$ is the weight loss rate, and $\rho$ is the density for the steel specimen $\left(7.85 \mathrm{~g} \mathrm{~cm}^{-3}\right.$ for the mild steel and $7.98 \mathrm{~g} \mathrm{~cm}^{-3}$ for the stainless steel).
After 14 day immersion tests, the ILs of IL + MO and IL + $\mathrm{MO}+\mathrm{H}_{2} \mathrm{O}_{2}$ systems in which stainless steel specimens were corroded were collected and processed for EDS and ODS experiments, respectively. The specimens were taken away from the IL solution after immersion period. The IL system was still a biphasic system. After settling the system for $2 \mathrm{~h}$, the mixture will become two layers, namely, the IL phase and the oil phase. The IL phase along with $\mathrm{H}_{2} \mathrm{O}$ or $\mathrm{H}_{2} \mathrm{O}_{2}$ was the lower layer. The model oil can be easily separated from the system by decantation. Then, the IL phase was distilled in a rotary evaporation at $80^{\circ} \mathrm{C}$ for $10 \mathrm{~h}$ to remove the residual water, hydrogen peroxide and model oil. In EDS and ODS experiments, the mass ratio of the IL to the model oil is 0.2 .

\section{Results and discussion}

\subsection{Weight loss measurement}

Fig. 2 shows the changes in color of [BMIM] $\mathrm{HSO}_{4}$ IL before and after corrosion of mild steel and stainless steel specimens. The color of pristine [BMIM] $\mathrm{HSO}_{4}$ is light yellow, and after immersion tests the IL solutions become darker. The change in color varies with different corrosion systems. According to the colorimetric properties of iron ion, ${ }^{\mathbf{4 1 , 4 2}}$ the darker of the color implies the higher concentration of the metallic iron and consequently the stronger corrosivity of IL solution. Therefore, by comparing the color in different IL solutions, it can be preliminarily deduced that the corrosivity of four IL solutions is in an order of IL $+\mathrm{MO}+\mathrm{H}_{2} \mathrm{O}_{2}>\mathrm{IL}+\mathrm{MO}+\mathrm{H}_{2} \mathrm{O}>\mathrm{IL}>\mathrm{IL}+\mathrm{MO}$.

There is an interesting phenomenon that the color of ILs appears to be yellow brown after corrosion of mild steel, while it is green in general after corrosion of stainless steel. It suggests that the primary form of the corrosion product in IL solutions is the ferric ion $\left(\mathrm{Fe}^{3+}\right)$ for mild steel and the ferrous ion $\left(\mathrm{Fe}^{2+}\right)$ for stainless steel, respectively. This hypothesis is confirmed by the Inductively Coupled Plasma Mass Spectrometry (ICP-MS) and spectrophotometer analyses. The type and the content of metal ions in different IL systems after corrosion of mild steel and stainless steel are listed in Table 1 , which are consistent with the changes in color of different IL systems.

The difference in the type of metal ions can be ascribed to the kinetics of ferrous oxidation that lower acidity is favorable for the conversion of $\mathrm{Fe}^{2+}$ to $\mathrm{Fe}^{3+} \cdot{ }^{43}$ As the mild steel experienced much more severe corrosion in IL solutions than the stainless steel, the hydrogen ion consumption should be greater and thus

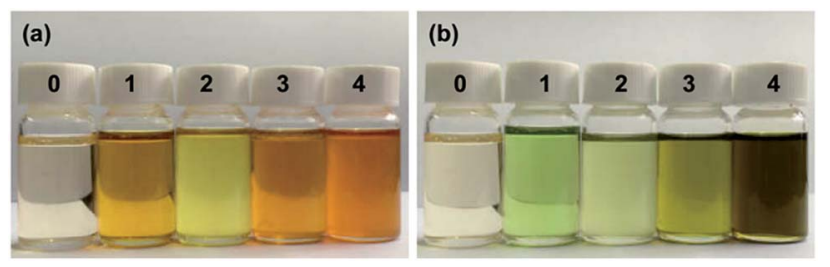

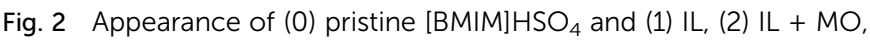
(3) $\mathrm{IL}+\mathrm{MO}+\mathrm{H}_{2} \mathrm{O}$, (4) $\mathrm{IL}+\mathrm{MO}+\mathrm{H}_{2} \mathrm{O}_{2}$ after immersion with (a) Q235, (b) SS316L at $45{ }^{\circ} \mathrm{C}$ for 14 days. (For color version of this figure, the reader is referred to the online version of this article). 
Table 1 The type and the content of metal ions in different IL systems after corrosion of mild steel and stainless steel at $45{ }^{\circ} \mathrm{C}$ for 14 days

\begin{tabular}{|c|c|c|c|c|c|}
\hline System & & $\mathrm{Fe}^{2+}(\mathrm{wt} \%)$ & $\mathrm{Fe}^{3+}(\mathrm{wt} \%)$ & $\mathrm{Cr}^{3+}(\mathrm{wt} \%)$ & $\mathrm{Ni}^{2+}(\mathrm{wt} \%)$ \\
\hline \multirow[t]{3}{*}{ Mild steel } & IL & 0.042 & 0.323 & - & - \\
\hline & $\mathrm{IL}+\mathrm{MO}$ & 0.074 & 0.237 & - & - \\
\hline & $\mathrm{IL}+\mathrm{MO}+\mathrm{H}_{2} \mathrm{O}_{2}$ & 0.159 & 0.624 & - & - \\
\hline \multirow[t]{2}{*}{ Stainless steel } & $\mathrm{IL}$ & 0.021 & 0.005 & 0.0025 & 0.0012 \\
\hline & $\mathrm{IL}+\mathrm{MO}$ & 0.016 & 0.003 & 0.0022 & 0.0012 \\
\hline
\end{tabular}

the acidity should be weaker in these systems. The acidity of different IL systems before and after corrosion of mild steel and stainless steel are evaluated from the determination of the Hammett acidity function $\left(H_{0}\right)$, calculated with the formula: ${ }^{44}$

$$
H_{0}=\mathrm{p} K(\mathrm{I})_{\mathrm{aq}}+\log \left([\mathrm{I}] /\left[\mathrm{IH}^{+}\right]\right)
$$

where $\mathrm{p} K(\mathrm{I})_{\mathrm{aq}}$ is the $\mathrm{p} K_{\mathrm{a}}$ value of the indicator referred to an aqueous solution, $[\mathrm{I}]$ and $\left[\mathrm{IH}^{+}\right]$are the molar concentrations of unprotonated and protonated forms of the indicator in the solvents, respectively.

The Brönsted acidity results are illustrated in Table 2 . The IL systems after corrosion of mild steel indeed have a weaker acidity than those after corrosion of stainless steel. As a consequence, the oxidization rate is greatly enhanced and finally $\mathrm{Fe}^{2+}$

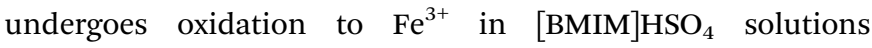
immersed with mild steel.

Fig. 3 shows the corrosion depth rates of mild steel and stainless steel specimens in different IL solutions. Primarily, it can be observed that stainless steel has a better corrosion resistance in all IL solutions than mild steel. In pure [BMIM] $\mathrm{HSO}_{4} \mathrm{IL}$, mild steel is attacked with a corrosion depth rate of $1.25 \mathrm{~mm} \mathrm{y}^{-1}$, and with addition of model oil, the corrosion depth rate exhibits a slight reduction to $1.15 \mathrm{~mm} \mathrm{y}^{-1}$. Mild steel suffers severe corrosion in aqueous IL solution with a corrosion depth rate of $1.64 \mathrm{~mm} \mathrm{y}^{-1}$, and in the presence of $\mathrm{H}_{2} \mathrm{O}_{2}$, the corrosion depth rate increases up to $1.78 \mathrm{~mm} \mathrm{y}^{-1}$. On the other

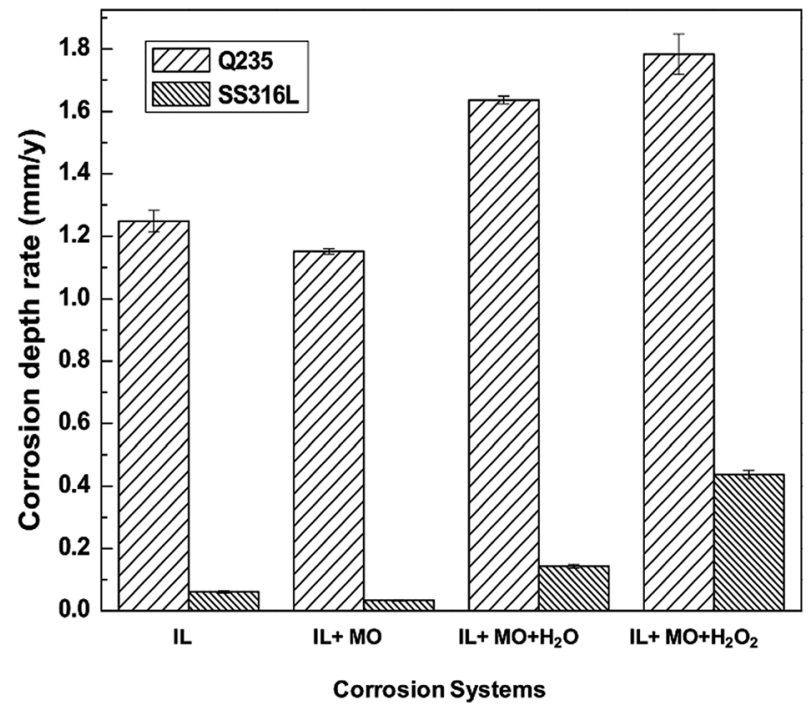

Fig. 3 Corrosion rate of steel specimens immersed in different [BMIM] $\mathrm{HSO}_{4}$ systems at $45^{\circ} \mathrm{C}$ for 14 days.

hand, the stainless steel has excellent performance in water free IL solutions, i.e., in IL and IL + MO systems, where the corrosion depth rates are only $0.06 \mathrm{~mm} \mathrm{y}^{-1}$ and $0.03 \mathrm{~mm} \mathrm{y}^{-1}$, respectively, below the target corrosion depth rate of $\max 0.1 \mathrm{~mm} \mathrm{y}^{-1}$ for the stainless steel. ${ }^{16}$ The presence of water and $\mathrm{H}_{2} \mathrm{O}_{2}$ significantly

Table 2 Calculation and comparison of the Hammett function of [BMIM] $\mathrm{HSO}_{4} \mathrm{ILs}\left(5 \times 10^{-5} \mathrm{~mol} \mathrm{L^{-1 }}\right)$ from different systems before and after corrosion of mild steel and stainless steel at $45^{\circ} \mathrm{C}$ for 14 days

\begin{tabular}{|c|c|c|c|c|c|}
\hline Systems & & $A_{\max }$ & [I] $(\%)$ & {$\left[\mathrm{IH}^{+}\right](\%)$} & $H_{0}$ \\
\hline Blank & & 1.305 & 100 & 0 & - \\
\hline \multirow[t]{3}{*}{ Before corrosion } & IL & 0.402 & 30.1 & 69.9 & 0.624 \\
\hline & $\mathrm{IL}+\mathrm{MO}+\mathrm{H}_{2} \mathrm{O}$ & 0.362 & 27.7 & 72.3 & 0.574 \\
\hline & $\mathrm{IL}+\mathrm{MO}+\mathrm{H}_{2} \mathrm{O}_{2}$ & 0.366 & 28.0 & 72.0 & 0.580 \\
\hline \multirow[t]{2}{*}{ After corrosion of stainless steel } & IL & 0.780 & 59.8 & 40.2 & 1.162 \\
\hline & $\mathrm{IL}+\mathrm{MO}+\mathrm{H}_{2} \mathrm{O}_{2}$ & 0.758 & 58.1 & 41.9 & 1.132 \\
\hline \multirow[t]{4}{*}{ After corrosion of mild steel } & IL & 1.046 & 80.2 & 19.8 & 1.598 \\
\hline & $\mathrm{IL}+\mathrm{MO}$ & 0.997 & 76.4 & 23.6 & 1.500 \\
\hline & $\mathrm{IL}+\mathrm{MO}+\mathrm{H}_{2} \mathrm{O}$ & 0.961 & 73.6 & 26.4 & 1.435 \\
\hline & $\mathrm{IL}+\mathrm{MO}+\mathrm{H}_{2} \mathrm{O}_{2}$ & 0.969 & 74.3 & 25.7 & 1.451 \\
\hline
\end{tabular}


enhances the corrosivity of IL systems that the corrosion rate of stainless steel increases to about $0.14 \mathrm{~mm} \mathrm{y}^{-1}$ and $0.44 \mathrm{~mm} \mathrm{y}^{-1}$, respectively, well above the $0.1 \mathrm{~mm} \mathrm{y}^{-1}$ target line.

The addition of $10 \%$ of water can significantly increase the corrosivity of [BMIM] $\mathrm{HSO}_{4}$. However, the corrosion depth rates of mild steel and stainless steel in $\mathrm{MO}+\mathrm{H}_{2} \mathrm{O}$ systems are only $0.12 \mathrm{~mm} \mathrm{y}^{-1}$ and $0.006 \mathrm{~mm} \mathrm{y}^{-1}$, respectively, which are far less than that in $\mathrm{IL}+\mathrm{MO}+\mathrm{H}_{2} \mathrm{O}$ systems. Uerdingen et al. reported that with the presence of $10 \%$ water, carbon steel was severely corroded in IL with methyl sulfate anion $\left(2.5 \mathrm{~mm} \mathrm{y}^{-1}\right) .{ }^{16}$ This was explained by the formation of sulfuric acid via hydrolysis of the methyl sulfate. In this work, the addition of $10 \%$ of water leads to a stronger acidity in $\mathrm{IL}+\mathrm{MO}+\mathrm{H}_{2} \mathrm{O}$ system than nonaqueous IL systems (see Table 2), which increases the corrosion depth rate of steel. Similarly, hydrogen peroxide is not corrosive to the steel as well that the corrosion depth rates of mild steel and stainless steel in $\mathrm{MO}+\mathrm{H}_{2} \mathrm{O}_{2}$ systems are only $0.007 \mathrm{~mm} \mathrm{y}^{-1}$ and $0.003 \mathrm{~mm} \mathrm{y}^{-1}$, respectively.

For $[\mathrm{BMIM}] \mathrm{HSO}_{4}$, the imidazolium cation plays as an inhibitor for steel while the anion of $\mathrm{HSO}_{4}{ }^{-}$is corrosive to the steel. It was reported that ILs with imidazolium cation have been employed as inhibitors for steel in $\mathrm{H}_{2} \mathrm{SO}_{4}$ solution. ${ }^{45}$ For example, the addition of 1-octyl-3-methylimidazolium bromide and 1-allyl-3-octylimidazolium bromide ionic liquids in $0.5 \mathrm{M}$ $\mathrm{H}_{2} \mathrm{SO}_{4}$ solutions can significantly decrease the corrosion rate. The corrosion depth rate of 316 stainless steel in $98 \% \mathrm{H}_{2} \mathrm{SO}_{4}$ is close to $0.13 \mathrm{~mm} \mathrm{y}^{-1},{ }^{46}$ which is higher than the corrosion depth rate of stainless steel in pure $[\mathrm{BMIM}] \mathrm{HSO}_{4}$ system, indicating the corrosion inhibition property of imidazolium cation of $[\mathrm{BMIM}] \mathrm{HSO}_{4}$. On the other hand, the corrosion property of ionic liquid with the anion of $\mathrm{HSO}_{4}{ }^{-}$is related to cation structure. The imidazolium cation is a better corrosion inhibitor than quaternary ammonium moiety. ${ }^{\mathbf{1 6}}$ The corrosion depth rate of $316 \mathrm{~L}$ stainless steel in 1-methylimidazole hydrogensulfate ([HMIM] $] \mathrm{HSO}_{4}$ ) was $0.011 \mathrm{~mm} \mathrm{y}^{-1}$, similar to the corrosion depth rate in $[\mathrm{BMIM}] \mathrm{HSO}_{4}\left(0.06 \mathrm{~mm} \mathrm{y}^{-1}\right)$. But the corrosion depth rate of stainless steel in $N$-triethylammonium sulfate $\left(\left[\mathrm{Et}_{3} \mathrm{NH}\right] \mathrm{HSO}_{4}\right)$ was $1.3 \mathrm{~mm} \mathrm{y}^{-1}$, which is more corrosive than imidazolium-based hydrogensulfate ILs. ${ }^{47}$

The weight loss of SS316L specimens in different IL solutions are shown as a function of time in Fig. 4. A continuous increase in weight loss at an approximately linear rate take places for SS316L in each IL systems. The weight loss rate constants and correlation coefficients are shown in Table S1 (see $\mathrm{ESI} \dagger$ ). The correlation coefficients $\left(R^{2}\right)$ of regression analyses approach to 1 , indicating that the corrosion kinetics is linear as the function of time for the weight loss of SS316L in four IL solutions.

To explain the experimental results, the corrosion mechanism of steel in various [BMIM] $\mathrm{HSO}_{4}$-based desulfurization systems is proposed. In acid media, metallic materials could be corroded via two distinct reactions, namely, hydrogen evolution corrosion and oxygen reduction corrosion.

As $[\mathrm{BMIM}] \mathrm{HSO}_{4}$ IL is a proton-conducting nonaqueous electrolyte in reaction, ${ }^{48}$ the cathodic and anodic reactions are written in the same form for the nonaqueous and aqueous IL

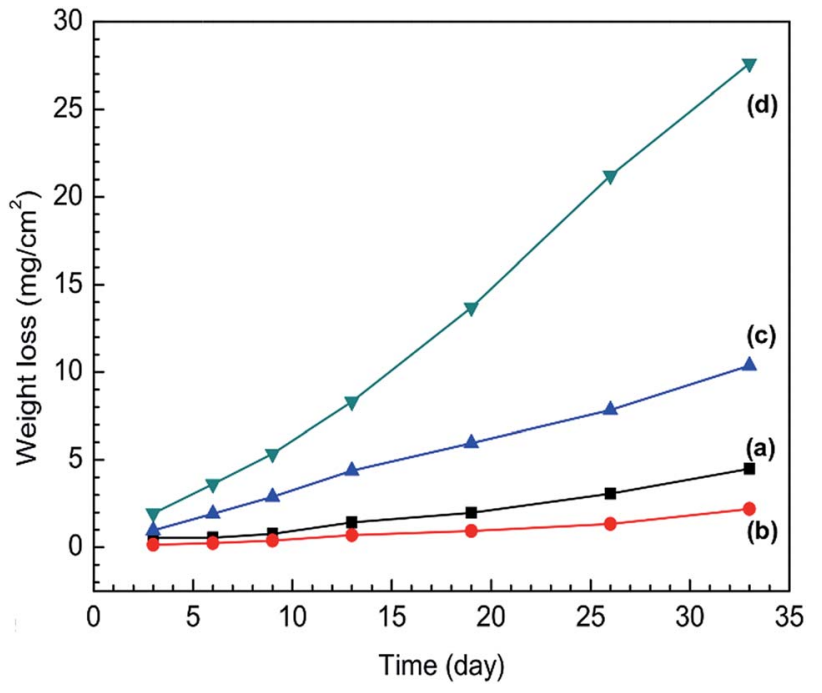

Fig. 4 Weight loss evolution of stainless steel specimens in (a) IL, (b) IL $+\mathrm{MO}$, (c) $\mathrm{IL}+\mathrm{MO}+\mathrm{H}_{2} \mathrm{O}$, (d) $\mathrm{IL}+\mathrm{MO}+\mathrm{H}_{2} \mathrm{O}_{2}$ as a function of time.

solutions. The hydrogen evolution corrosive process can be expressed as:

Anodic reaction (iron dissolution):

$$
\mathrm{Fe} \rightarrow \mathrm{Fe}^{2+}+2 \mathrm{e}^{-}
$$

For stainless steel, in addition to the dissolution of Fe, the anodic dissolution of $\mathrm{Cr}$ and $\mathrm{Ni}$ can also occur via the following reactions: ${ }^{49}$

$$
\begin{aligned}
& \mathrm{Cr} \rightarrow \mathrm{Cr}^{3+}+3 \mathrm{e}^{-} \\
& \mathrm{Ni} \rightarrow \mathrm{Ni}^{2+}+2 \mathrm{e}^{-}
\end{aligned}
$$

The mechanism is in accordance with the ICP results (Table 1).

Cathodic reaction (reduction of hydrogen ion):

$$
2 \mathrm{H}^{+}+2 \mathrm{e}^{-} \rightarrow \mathrm{H}_{2}
$$

The presence of water can decrease the cation-anion interaction and increase the number of $\mathrm{H}$-bond between anion and water, ${ }^{50}$ which could lead to an increase of the number of $\mathrm{H}^{+}$in the systems. This hypothesis has been demonstrated by the acidity measurements that the $\mathrm{IL}+\mathrm{MO}+\mathrm{H}_{2} \mathrm{O}$ system has a higher acidity than the nonaqueous IL systems, as illustrated in Table 2. As a result, the corrosion depth rate is enhanced and the steel suffers more severe attack in the aqueous IL systems ( $\mathrm{IL}+\mathrm{MO}+\mathrm{H}_{2} \mathrm{O}$ and $\mathrm{IL}+\mathrm{MO}+\mathrm{H}_{2} \mathrm{O}_{2}$ systems $)$ than in the nonaqueous systems (IL and IL + MO systems). In the nonaqueous systems, the corrosion depth rate is inhibited with the addition of MO, due to the DBT in MO working as an inhibitor via adsorption on steel surface. The mechanism of DBT adsorption on the steel surface is similar to the imidazolium ring of $[\mathrm{BMIM}] \mathrm{HSO}_{4}$ that the interaction takes place through heteroatoms and aromatic rings onto the active site of steel surface. ${ }^{21}$ 
At the same time, the steel can be corroded through oxygen reduction corrosion as well. ${ }^{51}$

Cathodic reaction:

$$
\mathrm{O}_{2}+4 \mathrm{e}^{-}+4 \mathrm{H}^{+} \rightarrow 2 \mathrm{H}_{2} \mathrm{O}
$$

However, this cathodic reaction is limited by the concentration of $\mathrm{O}_{2}$ in IL systems. ${ }^{52}$ This cathodic reaction unlikely happens in IL and IL + MO systems. In the presence of $\mathrm{H}_{2} \mathrm{O}_{2}$, the cathodic reaction can also take place via the following equation:

Cathodic reaction:

$$
\mathrm{H}_{2} \mathrm{O}_{2}+2 \mathrm{e}^{-}+2 \mathrm{H}^{+} \rightarrow 2 \mathrm{H}_{2} \mathrm{O}
$$

As $\mathrm{H}_{2} \mathrm{O}_{2}$ is a more powerful oxidant, and the concentration of $\mathrm{H}_{2} \mathrm{O}_{2}$ is relatively higher in IL $+\mathrm{MO}+\mathrm{H}_{2} \mathrm{O}_{2}$ system, which results in a faster cathodic reaction.

In addition, $\mathrm{H}_{2} \mathrm{O}_{2}$ can be easily decomposed into $\mathrm{O}_{2}$ and $\mathrm{H}_{2} \mathrm{O}$, enhancing the concentration of $\mathrm{O}_{2}$ in the IL system:

$$
2 \mathrm{H}_{2} \mathrm{O}_{2} \rightarrow \mathrm{O}_{2}+2 \mathrm{H}_{2} \mathrm{O}
$$

As a result, the steel suffers the most severe corrosion in the IL systems with the addition of $\mathrm{H}_{2} \mathrm{O}_{2}$.

\subsection{ATR-FTIR analysis}

The bonding information of pristine [BMIM] $\mathrm{HSO}_{4} \mathrm{IL}$ as well as the surface films on the steel specimens after immersion in different IL solutions were investigated by ATR-FTIR analysis, as illustrated in Fig. 5. The spectra of the surface films of the stainless steel immersed in corresponding IL solutions are almost the same as those of mild steel, suggesting that the adsorption of IL molecules on the stainless steel surface is similar to that on the mild steel, as illustrated in Fig. S1 (see $\mathrm{ESI} \dagger$ ).

No obvious band is observed from the spectrum of mild steel (see Fig. 5a). The spectrum of pristine $[\mathrm{BMIM}] \mathrm{HSO}_{4} \mathrm{IL}$ is shown in Fig. 5b. The bands at 3149 and $3105 \mathrm{~cm}^{-1}$ are attributed to the $\mathrm{C}-\mathrm{H}$ stretching vibration in imidazolium ring. The bands at 2962 and $2875 \mathrm{~cm}^{-1}$ are assigned to the aliphatic $\mathrm{C}-\mathrm{H}$ asymmetric and symmetric stretching vibration of alkyl chain. The bands at 1467 and $1571 \mathrm{~cm}^{-1}$ correspond to $\mathrm{C}=\mathrm{C}$ and $\mathrm{C}=\mathrm{N}$ stretching vibrations of imidazolium ring, respectively. The peaks at 1024 and $1229 \mathrm{~cm}^{-1}$ are assigned to the $\mathrm{S}-\mathrm{O}$ and $\mathrm{S}-\mathrm{OH}$ stretching vibrations of $\mathrm{HSO}_{4}{ }^{-53}$ The band at $1161 \mathrm{~cm}^{-1}$ indicate the stretching vibration of $\mathrm{C}-\mathrm{N}$. The band at $837 \mathrm{~cm}^{-1}$ is due to $\mathrm{C}-\mathrm{H}$ in-plane bending vibration of imidazolium ring and the band at $753 \mathrm{~cm}^{-1}$ can be assign to the $\mathrm{C}-\mathrm{H}$ out-of-plane bending vibration of imidazolium ring. ${ }^{38,54}$

By comparing the spectra in Fig. 5, it is found that the majority of the bands of pristine IL are observed in the spectra of the surface film on steel specimens immersed in different IL

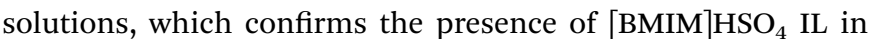
the surface films. However, it is remarkable that there are some distinctive differences in spectra between the surface film and the pristine IL:

(i) In the region of $1640-1650 \mathrm{~cm}^{-1}$, a new band is observed all over the four steel surfaces compared with the pristine $[\mathrm{BMIM}] \mathrm{HSO}_{4} \mathrm{IL}$. The new band can be ascribed to the formation

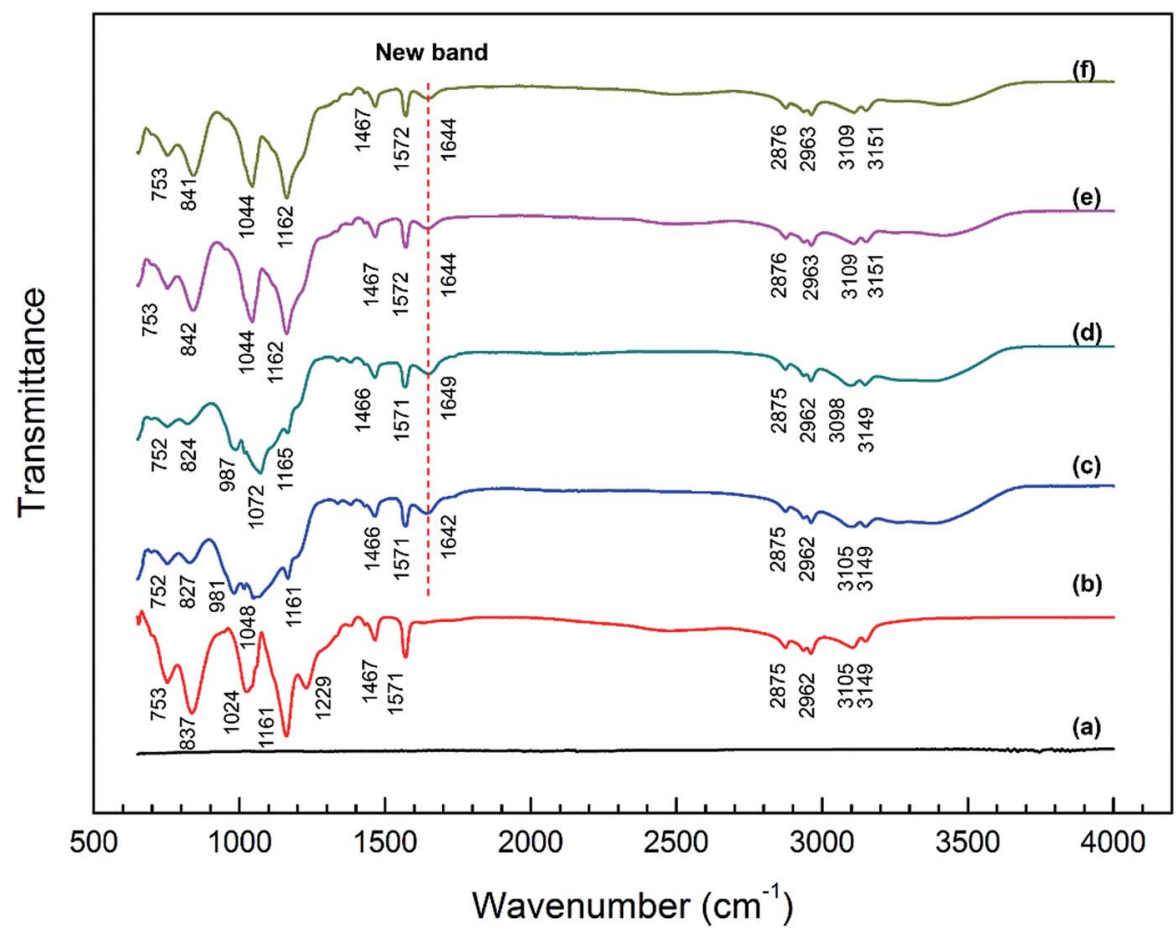

Fig. 5 IR spectra in a range of $650-4000 \mathrm{~cm}^{-1}$ of (a) mild steel, (b) pristine $[\mathrm{BMIM}] \mathrm{HSO}_{4}$ and surface films of mild steel specimens after immersion in (c) IL, (d) IL $+\mathrm{MO}$, (e) $\mathrm{IL}+\mathrm{MO}+\mathrm{H}_{2} \mathrm{O}$ and (f) $\mathrm{IL}+\mathrm{MO}+\mathrm{H}_{2} \mathrm{O}_{2}$ at $45^{\circ} \mathrm{C}$ for 14 days. 
of the surface chemical bond, i.e., $\mathrm{Fe}-\mathrm{N}$ bond in the interaction of the IL with the steel surface..$^{5,56}$

(ii) In the spectrum of steel surface immersed in pure IL (Fig. 5c), the bands appeared at 1024, 1161, and $1229 \mathrm{~cm}^{-1}$ in the spectra of pristine [BMIM] $\mathrm{HSO}_{4}$ are shifted to a broad band with multiple peaks at 981,1048 , and $1161 \mathrm{~cm}^{-1}$, which shows a possible interaction of the imidazolium groups of cation and $\mathrm{HSO}_{4}{ }^{-}$of anion with the steel surface. The quantum chemical property of $[\mathrm{BMIM}] \mathrm{HSO}_{4}$ showed that the highest occupied molecular orbital (HOMO) distributed in the anion while the lowest unoccupied molecular orbital (LUMO) distributed in the imidazolium group of cation. ${ }^{57}$ Hence, $[\mathrm{BMIM}] \mathrm{HSO}_{4}$ can easily interact with the steel surface by donating the electron from $\mathrm{HSO}_{4}{ }^{-}$to steel surface and accepting the electron from steel surface to the imidazolium ring. Meanwhile, the shift of peaks of $\mathrm{C}-\mathrm{N}$ bond to lower number has been demonstrated in previous research, ${ }^{54}$ when the imidazolium or analogue structure has an interaction with the metal surface. The spectrum of specimen immersed in IL + MO solution (Fig. 5e) is highly similar to that in Fig. $5 c$, implying a similar interaction of the IL molecules and the steel surface in IL + MO solution.

(iii) In the spectrum of specimen immersed in $\mathrm{IL}+\mathrm{MO}+\mathrm{H}_{2} \mathrm{O}$ solution (Fig. 5e), the bands of characteristic stretching vibration of S-O and $\mathrm{C}-\mathrm{N}$ shifted to 1162 and $1044 \mathrm{~cm}^{-1}$, which is different from Fig. $5 c$, revealing that the presence of water has an effect on the interaction between IL and steel. This phenomenon could be ascribed to the charge screening of water, ${ }^{50}$ which leads to an increase of hydrogen ions and a competitive adsorption against imidazolium ring. The spectrum of specimen immersed in $\mathrm{IL}+\mathrm{MO}+\mathrm{H}_{2} \mathrm{O}_{2}$ solution (Fig. $5 \mathrm{f}$ ) is almost the same as that in Fig. 5e.

There are no obvious changes in bands at $2800-3000 \mathrm{~cm}^{-1}$ in the spectra of steel surface, indicating that the aliphatic hydrocarbon chain in the IL molecule does not participate to the adsorption process.

From ATR-FTIR analysis, the IL film adsorbed on the metal surface is mainly by the interaction of imidazolium group of cation and $\mathrm{HSO}_{4}{ }^{-}$of anion with the metal surface. The interaction of imidazolium group with the metal surface can form a barrier between the steel and the corrosive environment and then inhibit the corrosion. The corrosion behavior of steel in different IL systems could be partly attributed to the interaction of the imidazolium group and the steel surface.

\subsection{Raman analysis}

To investigate the corrosion products of steel corroded by $[\mathrm{BMIM}] \mathrm{HSO}_{4}$ and $[\mathrm{BMIM}] \mathrm{HSO}_{4}$-based desulfurization systems, Raman spectrometer was applied to identify the compounds on the steel surface after immersion tests.

Fig. 6 shows the Raman spectra of corrosion products formed on mild steel surfaces after immersion tests. In these spectra, a strong and sharp peak at about $1018 \mathrm{~cm}^{-1}$ can be observed all over the mild steel surfaces, which is ascribed to the symmetric stretching vibrations of the sulfate ion in $\mathrm{FeSO}_{4}$ or $\mathrm{Fe}_{2}\left(\mathrm{SO}_{4}\right)_{3}$. The formation of $\mathrm{FeSO}_{4}$ or $\mathrm{Fe}_{2}\left(\mathrm{SO}_{4}\right)_{3}$ can be described as: $:^{\mathbf{5 8}}$

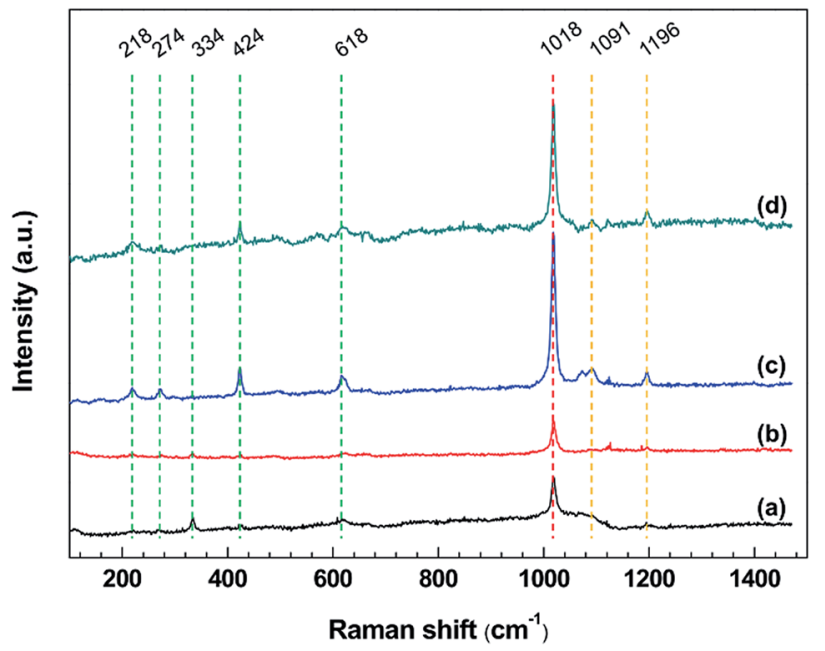

Fig. 6 Raman spectra in a range of $100-1500 \mathrm{~cm}^{-1}$ of mild steel surfaces after exposure to (a) IL, (b) IL $+\mathrm{MO}$, (c) IL $+\mathrm{MO}+\mathrm{H}_{2} \mathrm{O}$, (d) IL + $\mathrm{MO}+\mathrm{H}_{2} \mathrm{O}_{2}$ at $45^{\circ} \mathrm{C}$ for 14 days.

$$
\begin{gathered}
\mathrm{Fe}^{2+}+\mathrm{SO}_{4}{ }^{2-} \rightarrow \mathrm{FeSO}_{4} \\
2 \mathrm{Fe}^{3+}+3 \mathrm{SO}_{4}{ }^{2-} \rightarrow \mathrm{Fe}_{2}\left(\mathrm{SO}_{4}\right)_{3}
\end{gathered}
$$

The peaks at about $218,274,334$, and $618 \mathrm{~cm}^{-1}$ are attributed to the hematite $\left(\alpha-\mathrm{Fe}_{2} \mathrm{O}_{3}\right)$. In Fig. $6 \mathrm{c}$ and $\mathrm{d}$, a sharp peak appearing at $424 \mathrm{~cm}^{-1}$ suggests the formation of the $\mathrm{FeOOH}$ in the $[\mathrm{BMIM}] \mathrm{HSO}_{4}$ solution containing water. ${ }^{59}$ This is because Fe can react with $\mathrm{H}_{2} \mathrm{O}$ and $\mathrm{O}_{2}$ to form $\mathrm{FeOOH}$ via the following reaction:

$$
4 \mathrm{Fe}+3 \mathrm{O}_{2}+2 \mathrm{H}_{2} \mathrm{O} \rightarrow 4 \mathrm{FeOOH}
$$

There are some weak bands at about 1091 and $1196 \mathrm{~cm}^{-1}$, which are related to the vibration of the imidazolium ring that adsorbed on the steel surface, ${ }^{60}$ agreeing well with ATR-FTIR analysis. The intensity of Raman band at the same position varies with the specimen, due to the difference in the percentage of elemental composition on specimen surface. ${ }^{61}$ The Raman bands of some corrosion products $\left(\mathrm{Fe}_{2} \mathrm{O}_{3}\right.$ and $\mathrm{FeOOH}$ ) are slightly different from those reported in the literature,${ }^{17,59}$ possibly because the specific corrosion circumstance in this work.

The Raman spectra of stainless steel surface corroded by IL solutions are given in Fig. 7. In these spectra, the bands appearing at about 615 and $1018 \mathrm{~cm}^{-1}$ are similar to the spectra for mild steel, which could be assigned to $\alpha-\mathrm{Fe}_{2} \mathrm{O}_{3}$ and iron sulfate, respectively. However, these bands are broader and less distinct, indicating that the structure of compounds formed on the stainless steel is amorphous rather than crystalline. ${ }^{62}$ In addition, the bands located at about $840 \mathrm{~cm}^{-1}$ in the stainless steel samples are not present in the mild steel samples, which are corresponding to the $\mathrm{Cr}^{\mathrm{III}}$ oxide or $\mathrm{Cr}^{\mathrm{VI}}$ oxide. ${ }^{63,64}$ In the IL, $\mathrm{IL}+\mathrm{MO}$ and $\mathrm{IL}+\mathrm{MO}+\mathrm{H}_{2} \mathrm{O}$ systems, the formation of $\mathrm{Cr}^{\mathrm{III}}$ oxide with a low solubility in IL solutions provides the primary 


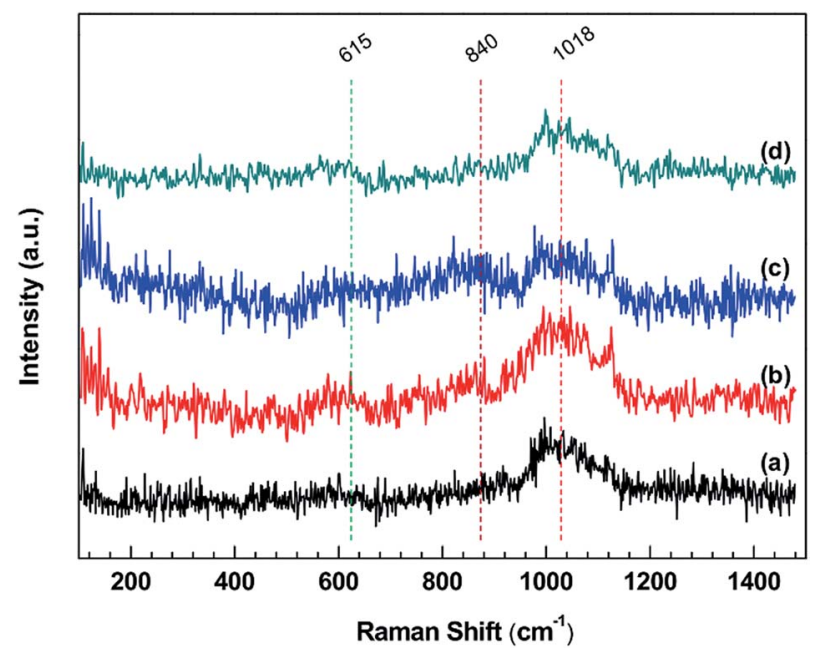

Fig. 7 Raman spectra in a range of $100-1500 \mathrm{~cm}^{-1}$ of stainless steel surfaces after exposure to (a) IL, (b) IL $+\mathrm{MO}$, (c) IL $+\mathrm{MO}+\mathrm{H}_{2} \mathrm{O}$, (d) IL + $\mathrm{MO}+\mathrm{H}_{2} \mathrm{O}_{2}$ at $45^{\circ} \mathrm{C}$ for 14 days.

corrosion resistance. Therefore, the corrosion rates of stainless steel in these systems are significantly lower than those of mild steel. In the presence of $\mathrm{H}_{2} \mathrm{O}_{2}$, the IL system becomes excessively oxidizing, where the dissolution of passive film occurs, specially by the oxidation of $\mathrm{Cr}^{\mathrm{III}}$ (as insoluble $\mathrm{Cr}_{2} \mathrm{O}_{3}$ ) to $\mathrm{Cr}^{\mathrm{VI}}$ (as soluble $\mathrm{Cr}_{2} \mathrm{O}_{7}{ }^{2-}$ ). This leads to a fast and accelerating transpassive corrosion, in the form of intergranular corrosion, ${ }^{\mathbf{6 5 , 6 6}}$ which is confirmed by the morphology results (see Fig. 8). The bands at 615 and $840 \mathrm{~cm}^{-1}$ are weak, which could be attributed to the amorphous structure of the compounds formed on the surface and the low content of the corrosion products. ${ }^{61,62}$
After the cleaning procedures, the surface of the specimens were analyzed by Raman spectrometer. The bands observed over the cleaned surfaces are extremely weak and almost invisible, as illustrated in Fig. S2 (see ESI $\dagger$ ). It can be considered that most of the corrosion products are removed from the specimen surfaces after the cleaning procedures.

\subsection{SEM observation}

The morphological changes of steel surfaces before and after immersion in IL solutions are monitored by SEM. The micrographs of the steel specimens without corrosion are shown in Fig. S3 (see ESI $\dagger$ ).

Fig. 8 shows the SEM of stainless steel surfaces after immersion in IL solutions. As illustrated in Fig. 8a, the pits with size of $1-2 \mu \mathrm{m}$ can be clearly seen on the rough surface of the stainless steel specimen immersed in pure IL. For the stainless steel immersed in IL + MO system (Fig. 8b), the stainless steel surface is less damaged as the size of pits is not exceeding $1 \mu \mathrm{m}$ and the original scratches can still be observed over the surface. In the IL solution with containing water (Fig. 8c), the stainless steel specimen is strongly corroded. Both the width and depth of the pits are increased. When adding $\mathrm{H}_{2} \mathrm{O}_{2}$ in the IL solution, the specimen suffers the most severe damage. The pits on the stainless surface are visible with a maximum width of nearly $10 \mu \mathrm{m}$ and a deep depth (Fig. 8d). The cross-section micrographs of stainless steel surfaces after immersion in IL + MO + $\mathrm{H}_{2} \mathrm{O}$ and $\mathrm{IL}+\mathrm{MO}+\mathrm{H}_{2} \mathrm{O}_{2}$ systems are shown in Fig. 9. In addition to the pitting corrosion, there also appears the intergranular corrosion over the surface, which is attributed to the polarization of the stainless steel specimen in its transpassive domain in $\mathrm{H}_{2} \mathrm{O}_{2}{ }^{40}$

Compared to stainless steel, mild steel exposed to the same IL solution suffers more severe corrosion by localized attack
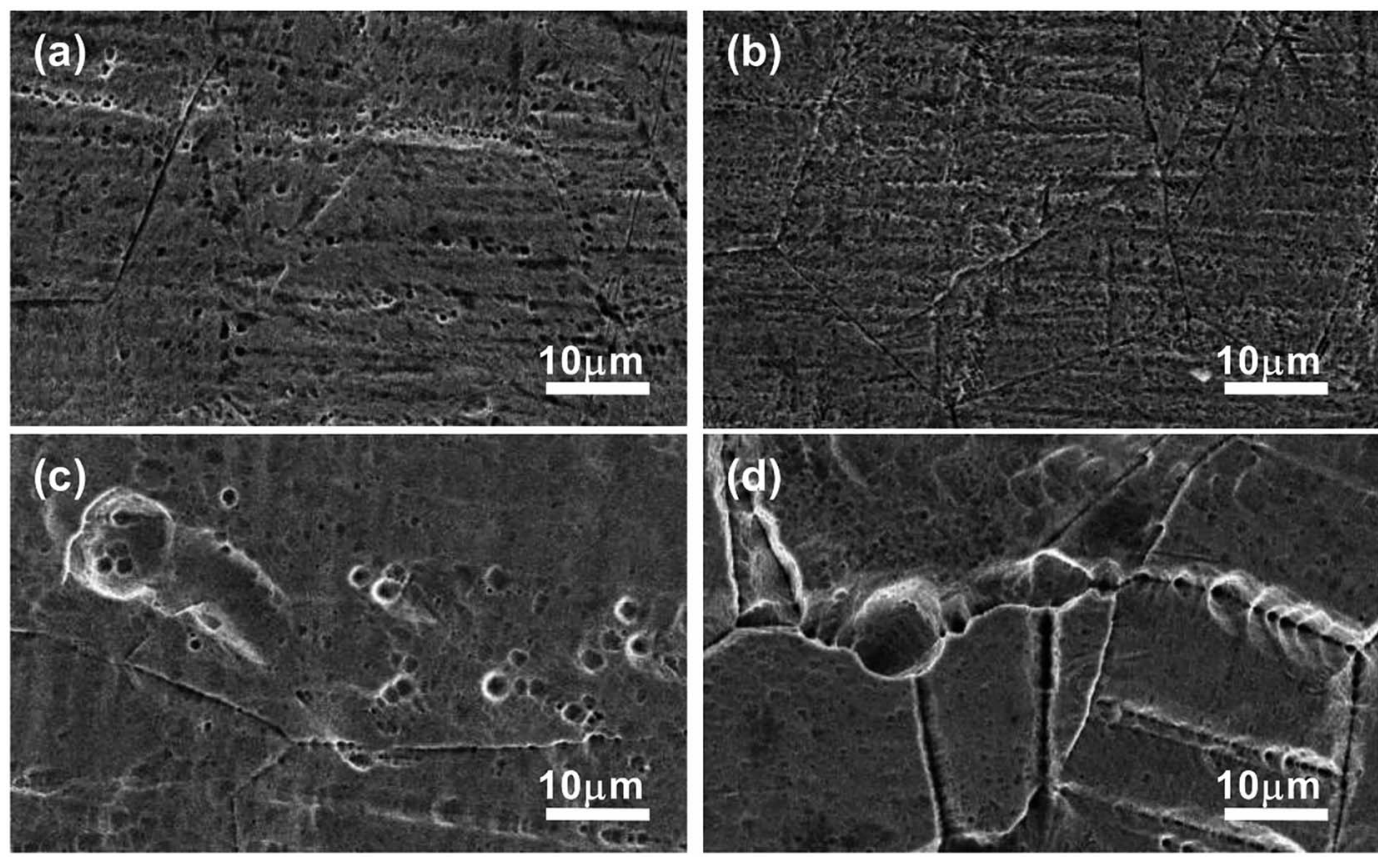

Fig. $8 \mathrm{SEM}$ of the surfaces of stainless steel after immersion in (a) IL, (b) IL $+\mathrm{MO}$, (c) IL $+\mathrm{MO}+\mathrm{H}_{2} \mathrm{O}$, (d) IL $+\mathrm{MO}+\mathrm{H}_{2} \mathrm{O}_{2}$ at $45^{\circ} \mathrm{C}$ for 14 days. 

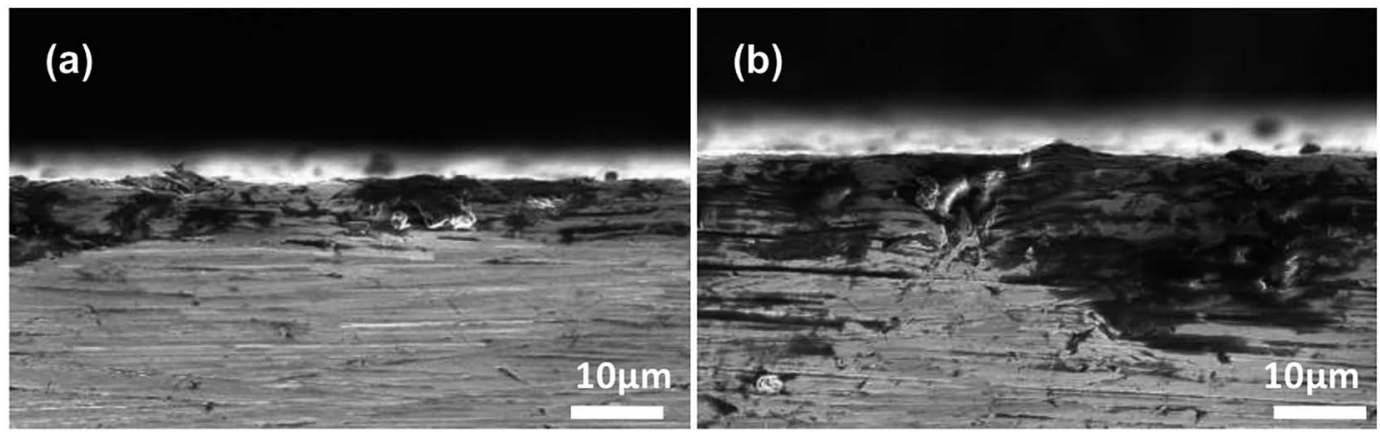

Fig. 9 SEM of the cross-section of stainless steel after immersion in (a) $\mathrm{IL}+\mathrm{MO}+\mathrm{H}_{2} \mathrm{O}$, (b) IL $+\mathrm{MO}+\mathrm{H}_{2} \mathrm{O}_{2}$ at $45^{\circ} \mathrm{C}$ for 14 days.

(see Fig. 10). The craters formed on mild steel surface are significantly greater and deeper than those on stainless steel, and the distribution and the shape of these craters are irregular.

From SEM observation, it can be seen that the severity of localized attack on stainless steel and mild steel is consistent in an increasing order of $\mathrm{IL}+\mathrm{MO}<\mathrm{IL}<\mathrm{IL}+\mathrm{MO}+\mathrm{H}_{2} \mathrm{O}<\mathrm{IL}+\mathrm{MO}+$ $\mathrm{H}_{2} \mathrm{O}_{2}$, which is in good agreement with the corrosion degree determined by weight loss measurement. The localized attack (pitting and/or intergranular corrosion) revealed by SEM could be a serious safety risk to the [BMIM] $\mathrm{HSO}_{4}$-based desulfurization systems for the industrial application.

\subsection{Effect of corrosion on desulfurization efficiency}

To investigate whether the corrosion processes have effect on the desulfurization efficiency of IL, the oxidative-extraction of DBT experiments using [BMIM] $\mathrm{HSO}_{4}$ IL before and after immersion were carried out at $45{ }^{\circ} \mathrm{C}$ under different $\mathrm{O} / \mathrm{S}$ molar ratios for $2 \mathrm{~h}$.
Fig. 11 displays the oxidative-extraction desulfurization efficiency of $[\mathrm{BMIM}] \mathrm{HSO}_{4} \mathrm{IL}$ before and after corrosion. When the pristine IL is used, the oxidative desulfurization efficiency increases at first and then decreases with increasing of $\mathrm{H}_{2} \mathrm{O}_{2}$. The removal of DBT increases sharply from $7 \%$ in the absence of $\mathrm{H}_{2} \mathrm{O}_{2}$ to more than $70 \%$ at the $\mathrm{O} / \mathrm{S}$ ratio getting to 5 , and then increases slowly to a plateau of $90 \%$ when the $\mathrm{O} / \mathrm{S}$ ratio is 20 . The sulfur removal drops as the dosage of $\mathrm{H}_{2} \mathrm{O}_{2}$ further increasing, which is possibly because the polarity of IL (the main driving force of desulfurization) is diluted with the high content of water. However, the desulfurization efficiency of $[\mathrm{BMIM}] \mathrm{HSO}_{4} \mathrm{IL}$ after corrosion is different to that of pristine IL. As the $\mathrm{O} / \mathrm{S}$ ratio increases from 0 to 5 , the removal of DBT from the model oil increases from $7 \%$ to $47 \%$, and then increases to $57 \%$ with the $\mathrm{O} / \mathrm{S}$ ratio reaching to 20 . The removal of sulfur has no evident change with further increase of $\mathrm{H}_{2} \mathrm{O}_{2}$.

It is clear that the corrosion of steel in $[\mathrm{BMIM}] \mathrm{HSO}_{4} \mathrm{IL}$ has changed the desulfurization capacity. The mechanism of IL
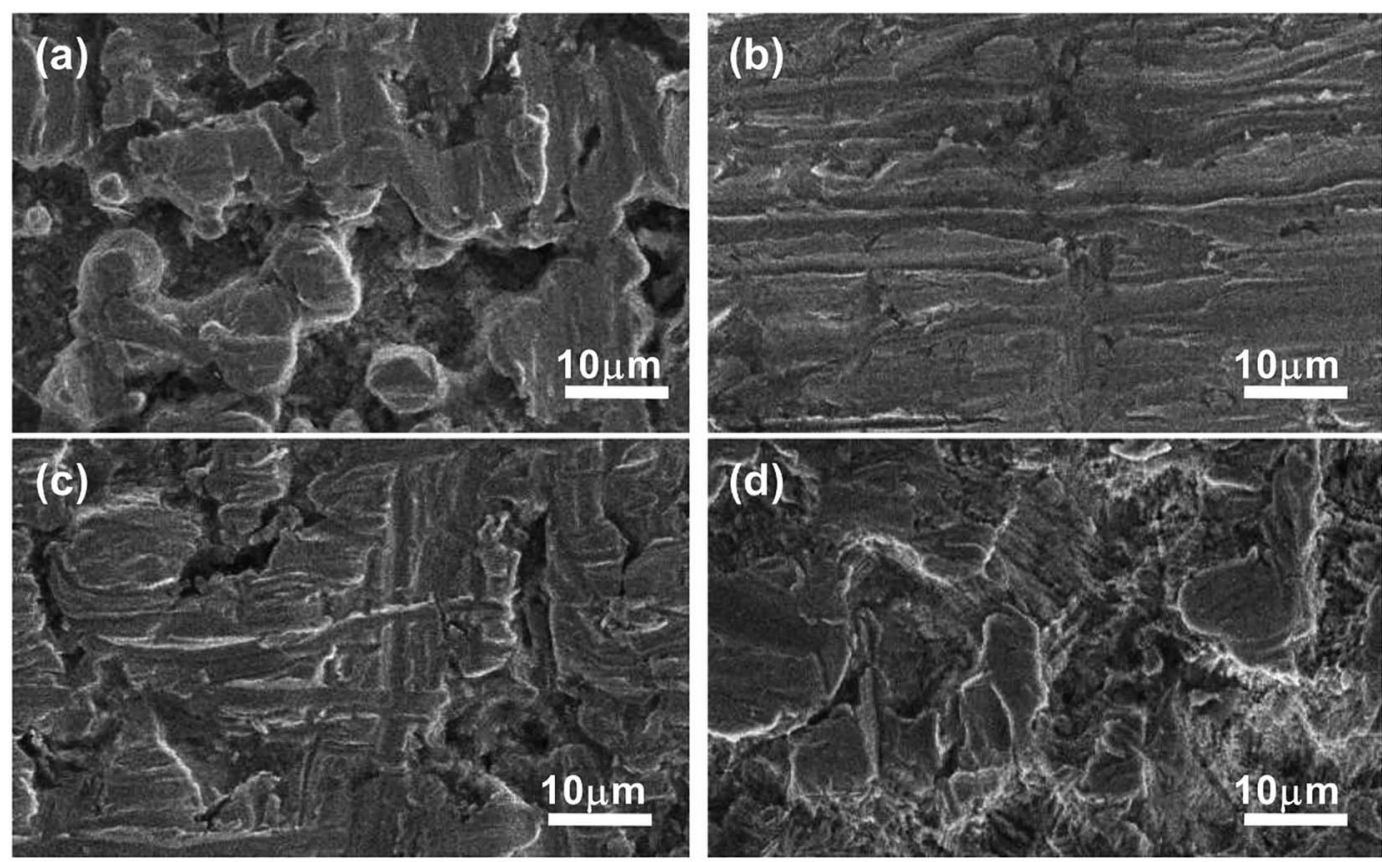

Fig. 10 SEM of the surfaces of mild steel after immersion in (a) IL, (b) IL $+\mathrm{MO}$, (c) IL $+\mathrm{MO}+\mathrm{H}_{2} \mathrm{O}$, (d) IL $+\mathrm{MO}+\mathrm{H}_{2} \mathrm{O}_{2}$ at $45^{\circ} \mathrm{C}$ for 14 days. 


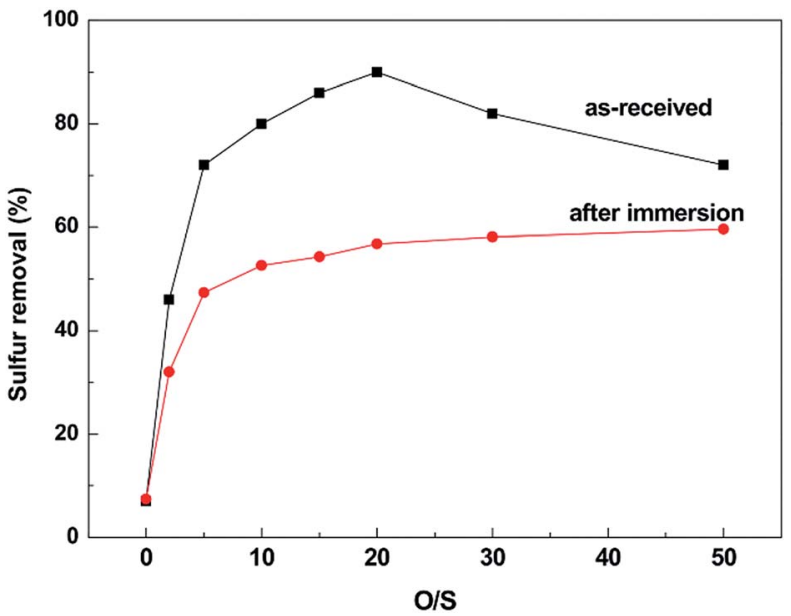

Fig. 11 Desulfurization efficiency of $[\mathrm{BMIM}] \mathrm{HSO}_{4}$ before and after corrosion of stainless steel at $45^{\circ} \mathrm{C}$ for 14 days.

extraction desulfurization of aromatic sulfur compounds such as DBT is mainly attributed to the $\pi-\pi$ interactions between the imidazolium group and aromatic ring. ${ }^{5,67}$ In the oxidation process, DBT is oxidized to $\mathrm{DBTO}_{2}$, which has much higher polarity than $\mathrm{DBT}^{8,68}$ and can be more easily inserted into the IL network. ${ }^{9}$ Thus, the oxidation of DBT can greatly enhance the desulfurization efficiency. In the oxidation process, acid is necessary for $\mathrm{H}_{2} \mathrm{O}_{2}$ decomposition, and the decomposition rate increases as the $\mathrm{pH}$ decreases. ${ }^{69}[\mathrm{BMIM}] \mathrm{HSO}_{4}$ can provide the hydrogen ion in oxidation process, which is benefit to the oxidization of DBT to $\mathrm{DBTO}_{2}$ in the IL phase. However, as stated above, the corrosion of steel has consumed considerable quantity of $\mathrm{H}^{+}$, leading to a weaker acidity, which will reduce the catalytic activity of [BMIM] $\mathrm{HSO}_{4}$ that the desulfurization efficiency is worse than pristine IL. Furthermore, the corrosion products transferred into the IL phase during the immersion tests, which also influences the removal of sulfur compounds that the metallic ion such as $\mathrm{Fe}^{3+}$ can form $\pi$ complexes with the aromatic sulfur compounds. ${ }^{4,7}$

In summary, the weakened acidity and the presence of corrosion products (iron ion) could be the two main reasons for the differences of desulfurization efficiency between ILs before and after corrosion.

\section{Conclusions}

The corrosion behavior of steel (mild steel and stainless steel) in [BMIM] $\mathrm{HSO}_{4}$-based desulfurization systems was investigated by weight loss measurements, ATR-FTIR, Raman and SEM from different aspects. The corrosion degree determined by all these methods are in good agreement, which is in an order of IL + MO $<\mathrm{IL}<\mathrm{IL}+\mathrm{MO}+\mathrm{H}_{2} \mathrm{O}<\mathrm{IL}+\mathrm{MO}+\mathrm{H}_{2} \mathrm{O}_{2}$. The addition of model oil can inhibit the corrosivity of IL media to some extent, while the presence of water or $\mathrm{H}_{2} \mathrm{O}_{2}$ enhances the corrosivity of IL solution.

From the combination of the changes in IL color and the ICP-MS and spectrophotometer and Raman analyses, iron sulfate proved to be the primary component of corrosion products, which are ferric ion $\left(\mathrm{Fe}^{3+}\right)$ for the mild steel and ferrous ion $\left(\mathrm{Fe}^{2+}\right)$ for the stainless steel, respectively. From ATRFTIR analysis, the adsorption of IL on the steel surface is mainly via the interaction of the imidazolium group of cation and $\mathrm{HSO}_{4}{ }^{-}$of anion with the metal surface, and the interaction is different between the water-free solutions and the aqueous solutions. SEM examination reveals that the steel suffers localized corrosion (pitting and/or intergranular corrosion) in IL solutions. The side effect of corrosion on the IL desulfurization efficiency is clearly suggested from the desulfurization experiments using pristine IL and IL after immersion tests. The differences in desulfurization efficiency are probably caused by the change of acidity and the existence of metallic ion in IL.

\section{Conflicts of interest}

There are no conflicts to declare.

\section{Acknowledgements}

This work is supported by National Natural Science Foundation of China (21406063, 21776074 and U1462123), Fundamental Research Funds for the Central Universities (222201514005).

\section{References}

1 J. F. Wishart, Energy Environ. Sci., 2009, 2, 956-961.

2 G. W. Meindersma, A. J. Podt and A. B. de Haan, Fuel Process. Technol., 2005, 87, 59-70.

3 Z. X. Lyu, T. Zhou, L. F. Chen, Y. M. Ye, K. Sundmacher and Z. W. Qi, Chem. Eng. Sci., 2014, 113, 45-53.

4 P. S. Kulkarni and C. A. Afonso, Green Chem., 2010, 12, 11391149.

5 O. V. Oliveira, A. S. Paluch and L. T. Costa, Fuel, 2016, 175, 225-231.

6 Z. Song, T. Zhou, Z. W. Qi and K. Sundmacher, ACS Sustainable Chem. Eng., 2017, 5, 3382-3389.

7 J. M. Campos-Martin, M. d. C. Capel-Sanchez, P. Perez-Presas and J. Fierro, J. Chem. Technol. Biotechnol., 2010, 85, 879-890.

8 D. Zhao, J. Wang and E. Zhou, Green Chem., 2007, 9, 12191222.

9 H. Lü, S. Wang, C. Deng, W. Ren and B. Guo, J. Hazard. Mater., 2014, 279, 220-225.

10 W. Zhang, K. Xu, Q. Zhang, D. Liu, S. Wu, F. Verpoort and X. M. Song, Ind. Eng. Chem. Res., 2010, 49, 11760-11763.

11 Z. Song, T. Zhou, J. Zhang, H. Cheng, L. Chen and Z. Qi, Chem. Eng. Sci., 2015, 129, 69-77.

12 Z. Song, J. Zhang, Q. Zeng, H. Cheng, L. Chen and Z. Qi, Fluid Phase Equilib., 2016, 425, 244-251.

13 T. L. Greaves and C. J. Drummond, Chem. Rev., 2008, 108, 206-237.

14 R. Abro, A. A. Abdeltawab, S. S. Al-Deyab, G. R. Yu, A. B. Qazi, S. R. Gao and X. C. Chen, RSC Adv., 2014, 4, 35302-35317.

15 R. Anantharaj and T. Banerjee, AIChE J., 2011, 57, 749-764.

16 M. Uerdingen, C. Treber, M. Balser, G. Schmitt and C. Werner, Green Chem., 2005, 7, 321-325. 
17 I. Molchan, G. Thompson, P. Skeldon, R. Lindsay, J. Walton, E. Kouvelos, G. E. Romanos, P. Falaras, A. Kontos and M. Arfanis, RSC Adv., 2015, 5, 35181-35194.

18 M. V. Diamanti, U. V. Velardi, A. Brenna, A. Mele, M. P. Pedeferri and M. Ormellese, Electrochim. Acta, 2016, 192, 414-421.

19 Y.-C. Wang, T.-C. Lee, J.-Y. Lin, J.-K. Chang and C.-M. Tseng, Corros. Sci., 2014, 78, 81-88.

20 I. Perissi, U. Bardi, S. Caporali and A. Lavacchi, Corros. Sci., 2006, 48, 2349-2362.

21 M. Mashuga, L. Olasunkanmi, A. Adekunle, S. Yesudass, M. Kabanda and E. Ebenso, Materials, 2015, 8, 3607-3632.

22 E. S. Sherif, H. Abdo and S. Abedin, Materials, 2015, 8, 38833895.

23 R. J. Wilbraham, C. Boxall, D. T. Goddard, R. J. Taylor and S. E. Woodbury, J. Nucl. Mater., 2015, 464, 86-96.

24 T. Zhou, L. Chen, Y. M. Ye, L. F. Chen, Z. W. Qi, H. Freund and K. Sundmacher, Ind. Eng. Chem. Res., 2012, 51, 6256-6264.

25 L. Alonso, A. Arce, M. Francisco, O. Rodriguez and A. Soto, AIChE J., 2007, 53, 3108-3115.

26 X. Chen, S. Yuan, A. A. Abdeltawab, S. S. Al-Deyab, J. Zhang, L. Yu and G. Yu, Sep. Purif. Technol., 2014, 133, 187-193.

27 R. Abro, A. Abdeltawab, S. Aldeyab, G. Yu, A. Qazi, S. Gao and X. Chen, RSC Adv., 2014, 4, 35302-35317.

28 J. L. Wang, D. S. Zhao, E. P. Zhou and Z. Dong, J. Fuel Chem. Technol., 2007, 35, 293-296.

29 A. D. Bokare and W. Choi, J. Hazard. Mater., 2015, 304, 313319.

30 Z. Song, D. Yu, Q. Zeng, J. J. Zhang, H. Y. Cheng, L. F. Chen and Z. W. Qi, Chin. J. Chem. Eng., 2017, 25, 159-165.

31 A. Standard, American Society for Testing and Materials G31-72, 2004.

32 T. Konstantinova, A. Spirieva and T. Petkova, Dyes Pigm., 2000, 45, 125-129.

33 J. J. Bell, T. E. Sargeant and J. A. Watson, J. Biol. Chem., 1976, 251, 1745-1758.

34 A. P. Hanza, R. Naderi, E. Kowsari and M. Sayebani, Corros. Sci., 2016, 107, 96-106.

35 R. P. Morco, A. Y. Musa, M. Momeni and J. Wren, Corros. Sci., 2016, 102, 1-15.

36 X. Li, S. Deng, H. Fu and G. Mu, Corros. Sci., 2009, 51, 620-634. 37 A. Yousefi, S. Javadian, N. Dalir, J. Kakemam and J. Akbari, RSC Adv., 2015, 5, 11697-11713.

38 C. Eaborn, The Sadtler Handbook of Infrared Spectra, ed. W.W. Simons, Heyden and Son, Ltd, London, 1978.

39 Z. Shi, M. Liu and A. Atrens, Corros. Sci., 2010, 52, 579-588.

40 B. Gwinner, M. Auroy, F. Balbaud-Célérier, P. Fauvet, N. Larabi-Gruet, P. Laghoutaris and R. Robin, Corros. Sci., 2016, 107, 60-75.

41 R. M. Cornell, U. Schwertmann, R. Cornell and U. Schwertmann, Mineral. Mag., 2003, 34, 740-741.

42 C. Fan, X. Huang, L. Han, Z. Lu, Z. Wang and Y. Yi, Sens. Actuators, B, 2015, 224, 592-599.

43 A. M. Jones, P. J. Griffin and T. D. Waite, Geochim. Cosmochim. Acta, 2015, 160, 117-131.
44 Z. Duan, Y. Gu, J. Zhang, L. Zhu and Y. Deng, J. Mol. Catal. A: Chem., 2006, 250, 163-168.

45 X. W. Zheng, S. T. Zhang, W. P. Li, M. Gong and L. L. Yin, Corros. Sci., 2015, 95, 168-179.

46 D. K. Louie, Handbook of Sulphuric Acid Manufacturing, DKL Engineering, Inc., Thornhill, Ontario, Canada, 2005.

47 D. J. Tao, X. M. Lu, J. F. Lu, K. Huang, Z. Zhou and Y. T. Wu, Chem. Eng. J., 2011, 171, 1333-1339.

48 Z. Du, Z. Li, S. Guo, J. Zhang, L. Zhu and Y. Deng, J. Phys. Chem. B, 2005, 109, 19542-19546.

49 A. Pardo, M. C. Merino, A. E. Coy, F. Viejo, R. Arrabal and E. Matykina, Corros. Sci., 2008, 50, 780-794.

50 T. C. Schutt, G. A. Hegde, V. S. Bharadwaj, A. J. Johns and C. M. Maupin, J. Phys. Chem. B, 2017, 121, 843-853.

51 A. Davydov, K. V. Rybalka, L. A. Beketaeva, G. R. Engelhardt, P. Jayaweera and D. D. Macdonald, Corros. Sci., 2005, 47, 195-215.

52 J. L. Anderson, J. K. Dixon and J. F. Brennecke, Cheminform, 2007, 39, 1208-1216.

53 Y. Chaker, H. Ilikti, M. Debdab, T. Moumene, E. Belarbi, A. Wadouachi, O. Abbas, B. Khelifa and S. Bresson, J. Mol. Struct., 2016, 1113, 182-190.

54 L. Feng, H. Yang and F. Wang, Electrochim. Acta, 2011, 58, 427-436.

55 M. A. Larrubia, G. Ramis and G. Busca, Appl. Catal., B, 2001, 30, 101-110.

56 G. Ramis and M. A. Larrubia, J. Mol. Catal. A: Chem., 2004, 215, 161-167.

57 J. Zhang, H. Cheng, L. Chen and Z. Qi, CIESC Journal, 2017, DOI: 10.11949/j.issn.0438-1157.20170232.

58 Y. S. Choi, S. Nesic and D. Young, Environ. Sci. Technol., 2010, 44, 9233-9238.

59 D. Larroumet, D. Greenfield, R. Akid and J. Yarwood, J. Raman Spectrosc., 2007, 38, 1577-1585.

60 M. Mączka, N. L. Marinho Costa, A. Gągor, W. Paraguassu, A. Sieradzki and J. Hanuza, Phys. Chem. Chem. Phys., 2016, 18, 13993-14000.

61 M. Ortiz-Morales, C. Frausto-Reyes, J. Soto-Bernal, S. AcostaOrtiz, R. Gonzalez-Mota and I. Rosales-Candelas, Spectrochim. Acta, Part A, 2014, 128, 681-685.

62 C. Joseph, P. Bourson and M. Fontana, J. Raman Spectrosc., 2012, 43, 1146-1150.

63 J. E. Maslar, W. S. Hurst, W. J. Bowers Jr, J. H. Hendricks, M. I. Aquino and I. Levin, Appl. Surf. Sci., 2001, 180, 102-118.

64 Y. Hedberg, J. Hedberg, Y. Liu and I. O. Wallinder, BioMetals, 2011, 24, 1099-1114.

65 J. Horvath and H. H. Uhlig, J. Electrochem. Soc., 1968, 115, 791-795.

66 P. Fauvet, F. Balbaud and R. Robin, J. Nucl. Mater., 2008, 375, 52-64.

67 H. Cheng, J. Zhang and Z. Qi, Mol. Simul., 2017, 1-8, DOI: 10.1080/08927022.2017.1337273.

68 E. Ito and J. R. Van Veen, Catal. Today, 2006, 116, 446-460. 69 G. Yu, S. Lu, H. Chen and Z. Zhu, Energy Fuels, 2005, 19, 447452. 